phẫu thuật rất quan trọng và xác định rò dưỡng chấp lượng nhiều hay ít, giúp phẫu thuật viên có hướng giải quyết sớm. Rò dưỡng chấp sau phẫu thuật có thể điều trị bảo tồn. Khi điều trị bảo tồn thất bại có thể can thiệp ngoại khoa thắt ống ngực.

\section{TÀl LIẸU THAM KHẢO}

1. Crumley R. L., Smith J. D. (1976) Postoperative chylous fistula prevention and management. Laryngoscope, 86 (6), 804-13.

2. de Gier H. H., Balm A. J., Bruning P. F., Gregor R. T., Hilgers F. J. (1996), Systematic approach to the treatment of chylous leakage after neck dissection. Head Neck, 18 (4), 347-51.

3. Lucente F. E., Diktaban T., Lawson W., Biller H. F. (1981), Chyle fistula management. Otolaryngol Head Neck Surg, 89 (4), 575-8.

4. Muthusami John C., Raj John P., Gladwin D. Gaikwad Pranay, Sylvester Shalom (2005), Persistent chyle leak following radical neck dissection: a solution that can be the solution. Annals of the Royal College of Surgeons of England, 87 (5), 379-379.
5. Nussenbaum B., Liu J. H., Sinard R. J. (2000), Systematic management of chyle fistula: the Southwestern experience and review of the literature. Otolaryngol Head Neck Surg, 122 (1), 31-8.

6. Rimensberger P. C., Müller-Schenker B., Kalangos A., Beghetti M. (1998), Treatment of a persistent postoperative chylothorax with somatostatin. Ann Thorac Surg, 66 (1), 253-4.

7. Rodgers G. K., Johnson J. T., Petruzzelli G. J., Warty V. S., Wagner R. L. (1992), Lipid and volume analysis of neck drainage in patients undergoing neck dissection. Am J Otolaryngol, 13 (5), 306-9.

8. Spiro J. D., Spiro R. H., Strong E. W. (1990), The management of chyle fistula. Laryngoscope, 100 (7), 771-4.

9. Stuart 'W. J. (1907), Operative Injuries of the Thoracic Duct in the Neck. Edinburgh Medical Journal, 22 (4), 301-317.

10. Knochel James P. (1985), Complications of total parenteral nutrition. Kidney International, 27 (3), 489-496.

\title{
BƯớC ĐẦU MÔ TẢ NỒNG Độ KHÁNG THỂ KHÁNG VI RÚT SARS-COV-2 SAU TIÊM VẮC XIN PHÒNG COVID-19
}

\section{TÓM TẮT}

Nghiên cứu đã tiến hành quan sát nồng độ kháng thể kháng vi rút SARS - CoV - 2 trên 80 đối tượing, bao gồm 9 đối tượng chưa tiêm vắc xin, 20 đối tượng đã được tiêm 1 mũi và 51 đối tương tiêm 2 mũi với hai mục tiêu 1) Mô tả đặc điểm đối tượng sử dụng xét nghiệm đinh lượng kháng thể sau khi tiêm vắc xin phòng ngừa Covid-19 2) Mô tả kết quả xét nghiệm định lượng nồng độ kháng thể kháng vi rút SARS CoV - 2 sau khi tiềm vắc xin phòng ngừa Covid-19. Kết luận: Các tác dụng không mong muốn phổ biến được ghi nhận sau khi tiêm vắc xin 1 mũi và mũi 2 là sốt, ớn lạnh, đau đâu, đau mỏi người và đau sưng tại vị trí tiêm. Tỷ lệ xuất hiện tác dụng không mong muốn ở cả 2 nhóm là tương đương. Kết quả định lượng kháng thể kháng vi rút SARS - CoV - 2 của mâuu nghiên cứu cho thây $100 \%$ các nhóm đã tiêm vắc xin đều có đáp ứng miên dịch với SARS - CoV - 2 ngay tù̀ mũi 1 và cao hơn so với nhóm chưa tiêm ít nhất 12 lần (nhóm tiêm 1 mũi) cho đến 71 lần (nhóm sau tiêm 2 mũi 2 tuần). Tiêm đủ 2 mũi vắc xin giúp cơ thể của các đối tương nghiên cứu đat được nồng độ kháng thể cao hơn rõ̃ rệt so với khi tiềm 1 mũi. Nồng độ kháng

\footnotetext{
${ }^{1}$ Bệnh viện Đa Khoa Quốc Tế Hải Phòng

2 Trường Đai hoc Y Dước Hải Phòng

Chịu trách nhiệm chính: Nguyễn Thanh Hồi

Email: hoinguyenthanhbm@gmail.com

Ngày nhận bài: 18.6.2021

Ngày phản biên khoa hoc: 11.8.2021

Ngày duyệt bài: 23.8.2021
}

Nguyễn Thanh Hồi ${ }^{1,2}$, Nguyễn Thị Thu Phương ${ }^{1,2}$

thể kháng vi rút SARS-Covid-2 vào tuân thứ 3 sau tiêm mũi 2 thấp hơn so với nhóm sau tiêm mũi 22 tuần. Từ kết quả phân tích trên, chúng ta thây rằng tiêm vắc xin phòng Covid-19 giúp sản sinh kháng thể chống lại vi rút SARS-CoV-2. Tuy nhiên, lượng kháng thể này khác nhau giữa các đối tượng và thay đổi theo thời gian sau khi tiêm phòng.

Tư khóa: Kháng thể kháng SARS - CoV - 2, vắc xin Covid-19

\section{SUMMARY \\ INITIAL DESCRIPTION OF ANTIBODY LEVELS AGAINST SARS - COV - 2 VIRUS AFTER VACCINATION AGAINST COVID-19}

The study observed the concentration of antibodies against SARS - CoV - 2 virus on 80 subjects, including 9 subjects who had not been vaccinated, 20 subjects received 1 dose of vaccine and 51 subjects received 2 doses with two objectives 1 ) Characterization of subjects using quantitative antibody testing after vaccination against Covid-19 2) Description of test results to quantify antibody levels against SARS - CoV - 2 after being vaccinated against Covid-19. Conclusion: Common adverse effects reported after vaccination with 1 dose and 2 doses were fever, chills, headache, body aches and pain and swelling at the injection site. The percentage of subjects with pain and swelling at the injection site accounted for the highest rate in both groups, this rate accounted for $60 \%$ in the group after $1^{\text {st }}$ injection and $74,5 \%$ in the group after $2^{\text {nd }}$ dose of vaccin. We recorded the rate of occurrence of human fatigue 
ranked second in both groups, common fever after the 2nd injection accounted for $26 \%$ and some unwanted side effects were less chill, headache. The results of IgG quantification of the study sample showed that $100 \%$ of the vaccinated groups had an immune response to SAR-COVID-2 right from the 1st dose and higher than the unvaccinated group at least 12 times (the vaccinated group of 1 dose) up to 71 times (group after 2 injections 2 weeks). Injecting 2 full doses of vaccine helped the body of research subjects achieve significantly higher antibody levels than when injecting 1 dose. The concentration of antibodies against the SARS-Covid-2 virus at the 3rd week after the 2nd injection was lower than the 2nd week after the 2nd injection. From the above analysis results, we indicated that vaccination against Covid-19 helps to produce antibodies against SARS-CoV-2 virus. However, the amount of this antibody varied between subjects and changed over time after vaccination. weeks, this concentration decreased by $2 / 3$ after 2 weeks after administration the second dose.

Keywords: Antibodies against SARS - CoV - 2, Covid-19 vaccine

\section{I. ĐẠT VẤN ĐỀ}

COVID-19 và các biến thể hiện nay là đại dịch truyền nhiễm với tác nhân gây bệnh là vi rút SARS-CoV-2 đang diễn ra trên phạm vi toàn cầu. Một trong các biểu hiện nặng của bệnh là hội chứng hô hấp cấp tính nghiêm trọng ảnh hưởng thảm khốc đến toàn thế giới dẫn đến hơn 3,8 triệu người tử vong trên toàn thế giới [1]. Từ khi đại dịch Covid-19 xuất hiện, hệ thống y tế hiện đại trên toàn cầu đã rơi vào tình trạng quá tải dẩn đến một cuộc khủng hoảng sức khỏe toàn cầu có hậu quả nặng nề nhất, hàng triệu bác sĩ, nhân viên y tế bị mắc bệnh phải phát tín hiệu cầu cứu đến chính phủ. Ngay trong thời điểm khẩn cấp, việc thúc đẩy sản xuất vắc xin là vấn đề cực kỳ bức thiết được Tổ chức y tế thể giới (WHO) phát động trên toàn hệ thống y tế quốc tế nhắm chấm dứt đại dịch toàn cầu. Đáp ứng với vắc xin nhìn chung đã được chứng minh là khác nhau giữa các cá thể [2]. Do vậy, nghiên cứu về khả năng sản sinh kháng thể sau khi tiêm vắc xin vô cùng quan trọng trong việc phát triển vắc xin và tìm ra các chiến lược hợp lý trước sự tràn lan và xuất hiên biến chủng mới của vi rút này. Tại Việt Nam chưa có đề tài nào nghiên cứu nào được thực hiện nhằm tìm hiểu về khả năng sản sinh kháng thể IgG sau khi tiêm vắc xin phòng Covid-19. Trong thời gian qua, bệnh viên Đa khoa Quốc tế Hải Phòng đã tham gia chiến dịch tiêm phòng vắc xin Covid-19 cho các đối tượng theo kế hoạch phân công của Sở Y tế Hải phòng. Để đánh giá khả năng miễn dịch với vi rút SARS-CoV-2 thông qua sự sản sinh kháng thể để chống lại vi rút, bệnh viện đã tiến hành đánh giá sơ bộ nồng độ kháng thể kháng vi rút SARSCoV-2 dựa trên kỹ thuật miễn dịch đánh dấu sử dụng công nghệ hóa phát quang tự động nhằm mục tiêu chính 1) Mô tả đặc điểm đối tượng xét nghiệm định lượng kháng thể sau khi tiêm vắc xin phòng ngưa Covid-19. 2) Mô tả kêt quả định lượng nồng độ kháng thể sau khi tiêm vắc xin phòng ngừa Covid-19.

\section{II. ĐỐI TƯỢNG VÀ PHƯƠNG PHÁP NGHIÊN CỨU}

Đối tượng nghiên cứu. Đối tượng nghiên cứu được lựa chọn ngẫu nhiên theo các tiêu chuẩn sau:

\section{Tiêu chuân lựa chọn:}

- Nhóm đã được tiêm vắc xin tại Bệnh viện đa khoa Quốc Tế Hải Phòng: lựa chọn ngẫu nhiên phân tầng trên 2 nhóm 1) nhóm sau tiêm 01 mũi 21 ngày 2) Nhóm sau tiêm 2 mũi

- Nhóm chưa được tiêm vắc xin (nhóm chứng): lựa chọn ngấu nhiên từ danh sách nhân viên bệnh viện chưa được tiêm vắc xin.

\section{Tiểu chuân loại trứ:}

- BN có tiên sử mắc Covid-19

- Bệnh nhân có tiêm thêm loại vắc xin khác không phải để phòng Covid-19 trong vòng 14 ngày trước ngày định lượng kháng thế.

Địa điểm và thời gian nghiên cứu. Nghiên cứu được tiến hành từ 04 đến tháng 08 năm 2021 tại bệnh viện Đa khoa Quốc tế Hải Phòng

Thiết kế nghiên cứu. Nghiên cứu được tiến hành theo phương pháp tiến cứu, không can thiệp

Cõ̃ mẩu nghiên cứu. Cõ̃ mẫu của nghiên cứu là 80 hồ sơ đáp ứng tiêu chuẩn lựa chọn và tiêu chuẩn loại trừ của nghiên cứu.

Phương pháp chọn mẫu. Nghiên cứu chọn mẫu theo phương pháp thuận tiện. Nhóm nghiển cứu lấy toàn bộ kết quả mẫu bệnh phẩm của bệnh viện phù hợp các tiêu chuẩn lựa chọn và loại trừ của nghiên cứu.

Biến số nghiên cứu: Muc tiêu 1: Mô tả đặc điểm đối tượng xét nghiệm định lượng kháng thể sau khi tiêm vắc xin phòng ngừa Covid-19.

Mục tiêu 2: Mô tả kết quả định lượng nồng độ kháng thể sau khi tiêm vắc xin phòng ngừa Covid-19.

Phương pháp thu thập thông tin. Thông tin trong nghiên cứu được thu thập theo phương pháp quan sát, phỏng vấn và hồi cứu hồ sơ lưu trữ tại phần mềm bệnh án điện tử và phòng kế hoạch tổng hợp của bệnh viện.

Phương pháp xử lý và phân tích số liệu. Phương pháp định lượng kháng thể dựa trên kỹ thuật miễn dịch đánh dấu sử dụng công nghệ hóa phát quang tự động. Các đối tượng trong 
nghiên cứu được lấy mẫu xét nghiệm bằng test Liaison Sars-CoV-2 IgG, giới hạn trên 400 $\mathrm{AU} / \mathrm{mL}$, giới hạn dưới $0.3 \mathrm{AU} / \mathrm{mL}$. Xét nghiệm kháng thể với kết quả $\geq 15(\mathrm{AU} / \mathrm{mL})$ được xác định là có đáp ứng miễn dịch với vi rút SARSCoV-2, trong khi đó nếu kết quả $<12(\mathrm{AU} / \mathrm{mL})$ được hiểu là chưa có đáp ứng miễn dịch, 12-15 $(\mathrm{AU} / \mathrm{mL})$ được coi là đáp ứng trung gian.

Dữ liệu được nhập và xử lí trên phần mềm SPSS 19. Các biến định tính được tính bằng tân suất và phần trăm, các biến định lượng được tính bằng trung bình và độ lệch chuẩn. Kiểm tra mối quan hệ giữa hai biến định tính bằng phép thử Chi square, giữa biến định tính và biến định lượng bằng T-test. Sự khác nhau có ý nghĩa thống kê khi $p<0,05$.

Đạo đức nghiên cứu. Nghiên cứu được sự chấp thuận bởi Hội đồng Đạo đức Bệnh viện Đa khoa quốc tế Hải Phòng và các đối tượng tham gia nghiên cứu.

\section{KẾT QUẢ NGHIÊN CỨU}

3.1. Đăc điểm đối tượng xét nghiệm kháng thể phòng Covid-19. Trong 80 đối tượng có xét nghiệm định lượng kháng thể phòng ngừa Covid-19, có 9 đối tượng chưa tiêm vắc xin, có 20 đối tượng đã tiêm 1 mũi vắc xin trên 21 ngày, có 51 đối tượng sau khi tiêm 2 mũi. Trong số 51 đối tượng sau khi tiêm 2 mũi, có 15 đối tượng tiêm 2 mũi sau một tuần, 3 đối tượng tiêm 2 mũi sau hai tuần, 32 đối tượng tiêm 2 mũi sau 3 tuần. Tất cả các đối tượng ở các nhóm đã được tiêm vắc xin đều được tiêm vắc xin Astrazeneca. Đặc điểm các đối tượng xét nghiệm định lượng kháng thể phòng Covid-19 thể hiện ở bảng 1 như sau:

Bảng 1: Đặc điểm đôî tượng xét nghiệm định lượng kháng thể phòng Covid-19 $(n=80)$

\begin{tabular}{|c|c|c|c|}
\hline Đặc điểm & $\begin{array}{c}\text { Nhóm } \\
\text { chưa tiêmm } \\
(n=9)\end{array}$ & \begin{tabular}{|c|} 
Nhóm sau \\
tiêm mữi 1 \\
$(n=20)$
\end{tabular} & $\begin{array}{l}\text { Nhóm sau } \\
\text { tiêm mữi } \\
(\mathrm{n}=51)\end{array}$ \\
\hline $\begin{array}{l}\text { Tuối, trung } \\
\text { vị (tứ phâr } \\
\text { vị) }\end{array}$ & $\begin{array}{c}34,0(25,5- \\
40,5)\end{array}$ & \begin{tabular}{|c|}
$39,0(30,3-$ \\
$56,3)$
\end{tabular} & $\begin{array}{c}28,0(32,0- \\
48,0)\end{array}$ \\
\hline $\begin{array}{c}\text { Giới nam, } \\
\mathrm{n}(\%)\end{array}$ & $1(11,1)$ & $6(30,0)$ & $18(35,3)$ \\
\hline $\begin{array}{c}\text { Có thuốc } \\
\text { dùng kèm, } \\
n(\%), \\
(\mathrm{n}=80)\end{array}$ & $2(22,2)$ & $2(10,0))$ & $6(11,8)$ \\
\hline $\begin{array}{c}\text { Có bệnh } \\
\text { mắc kèm, } \\
\text { n(\%), } \\
(\mathrm{n}=80)\end{array}$ & $2(22,2)$ & $4(20,0)$ & $8(15,7)$ \\
\hline
\end{tabular}

Đặc điểm về tuổi ở nhóm chưa tiêm, nhóm sau tiêm vắc xin mũi 1 , nhóm sau tiêm vắc xin mũi 2 có trung vị lần lượt là 34,39 và 28 . Về đặc điểm giới tính của các nhóm, nghiên cứu của chúng tôi ghi nhận tỷ lệ giới nam ít hơn ở cả 3 nhóm, nhóm chưa tiêm có $1 \%$, nhóm sau tiêm mũi 1 có $30 \%$, và nhóm sau tiêm mũi 2 có $35,3 \%$ là nam giới. Ở nghiên cứu của chúng tôi, tỷ lệ các đối tượng sử dụng thuốc dùng kèm và có bệnh mắc kèm tương đối thấp. Tỷ lệ sử dụng thuốc dùng kèm ở nhóm chưa tiêm, nhóm sau tiêm mũi 1 và nhóm sau tiêm mũi 2 lần lượt là $22,2 \%, 10,0 \%$ và $11,8 \%$. Tỷ lệ các đối tượng có bệnh mắc kèm ở nhóm chưa tiêm, nhóm sau tiểm mũi 1 và nhóm sau tiêm vắc xin mũi 2 lần lượt là $22,2 \%, 20,0 \%$ và $15,7 \%$.

\section{2. Đặc điểm các tác dụng mong muốn} sau khi tiêm phòng vắc xin Covid-19

Các tác dụng không mong muốn được ghi nhận tại thời điểm sau khi các đối tượng được tiêm vắc xin mũi 1 và mũi 2 thể hiện ở bảng 2 .

Bảng 2: Theo dối các tác dụng không mong muốn sau tiêm vắc xin phòng Covid$19(n=71)$

\begin{tabular}{|c|c|c|c|}
\hline Tiêu chí & $\begin{array}{c}\text { Nhóm sau } \\
\text { tiêm mũi } 1 \\
(n=20)\end{array}$ & $\begin{array}{c}\text { Nhóm sau } \\
\text { tiêm mữi } 2 \\
(n=51)\end{array}$ & $\begin{array}{c}\text { p- } \\
\text { value }\end{array}$ \\
\hline \begin{tabular}{|} 
Số bệnh nhân xuất \\
hiện tác dụng \\
không mong \\
muốn, n(\%)
\end{tabular} & $16(80)$ & $46(90,2)$ & 0,26 \\
\hline Sốt, $\mathrm{n}(\%)$ & $4(20,0)$ & $26(51,0)$ & 0,03 \\
\hline Ớn lạnh, n(\%) & $2(10,0)$ & $13(25,5)$ & 0,20 \\
\hline Đau đâu, n(\%) & $4(20,0)$ & $15(29,4)$ & 0,56 \\
\hline $\begin{array}{c}\text { Đau mỏi người, } \\
n(\%)\end{array}$ & $6(30,0)$ & $28(54,9)$ & 0,07 \\
\hline $\begin{array}{l}\text { Đau, sưng tại } \\
\text { vị trí tiêm n(\%) }\end{array}$ & $12(60,0)$ & $38(74,5)$ & 0,26 \\
\hline
\end{tabular}

Các tác dụng không mong muốn được ghi nhận ở các thời điểm sau khi tiêm vắc xin 1 mũi và 2 mũi là sốt, ớn lạnh, đau đầu, đau mỏi người và đau sưng tại vị trí tiêm. Tỷ lệ bệnh nhân xuất hiện sau tiêm mũi $1(80 \%)$ và mũi $2(90,2 \%)$ không có sự khác biệt với $p$-value $=0,26$. Đối tượng sau tiêm mũi 1 và mũi 2 gặp các tác dụng không mong muốn bao gồm ớn lạnh, đau đầu, đau mỏi người và đau, sưng tại vị trí tiêm tương đương nhau $(p>0,05)$. Tuy nhiên, sau khi tiêm mũi 2 có $51 \%$ (26/51) đối tượng gặp tác dụng phụ là sốt, tỷ lệ này cao hơn có ý nghĩa thống kê so với nhóm đối tượng tiêm mũi 1 (20\% (4/20)) với $p$-value $=0,03$

3.3. Đặc điểm kết quả xét nghiệm định lượng nồng độ kháng thể. Kết quả xét 
nghiệm định lượng nồng độ kháng thể của các đối tượng chưa tiêm vắc xin và sau khi tiêm vắc xin 1 mũi, 2 mũi sau 1 tuần, 2 tuần, 3 tuần được thể hiện ở bảng 3 .

Bảng 3: Kêt quả xét nghiệm định lượng kháng thể phòng Covid-19 (n=80)

\begin{tabular}{|c|c|}
\hline Nhóm & $\begin{array}{c}\text { Nồng đố kháng thể } \\
\text { kháng SARS-Covid-2 } \\
\text { (AU/ml), trung vị (tứ } \\
\text { phân vị) }\end{array}$ \\
\hline $\begin{array}{c}\text { Nhóm chưa tiêm vắc } \\
\text { xin }(n=9)\end{array}$ & $5,6(5,1-6,9)$ \\
\hline $\begin{array}{c}\text { Nhóm đã tiêm vắc xin } 1 \\
\text { mũi }(n=20)\end{array}$ & $69,25(38,7-100,75)$ \\
\hline $\begin{array}{c}\text { Nhóm sau tiêm vắc xin } \\
\text { 2 mũi } 1 \text { tuần ( } n=16)\end{array}$ & $250(183-400)$ \\
\hline $\begin{array}{c}\text { Nhóm sau tiêm vắc xin } \\
\text { 2 mũi } 2 \text { tuần }(n=3)\end{array}$ & $400(174-400)$ \\
\hline $\begin{array}{c}\text { Nhóm sau tiêm vắc xin } \\
2 \text { mũi } 3 \text { tuần ( } n=32)\end{array}$ & $123(77,1-187,5)$ \\
\hline$p$-value & $<0,05$ \\
\hline
\end{tabular}

Kết quả định lượng IgG của mấu nghiên cứu cho thây $100 \%$ các nhóm đã tiêm vắc xin đều có đáp ứng miễn dịch với SAR-COVID-2. Nồng độ kháng thể IgG có sự khác biệt giữa nhóm đối tượng tiêm mũi 1 và đối tượng tiêm đủ 2 mũi. Đồng thời, nồng độ này cũng thay đổi theo thời gian sau khi tiêm mũi 2 . Cụ thể, nhóm chưa tiêm vắc xin, không có tiền sử mắc Covid trước đó có trung vị nồng độ kháng thể là $5,6 \mathrm{AU} / \mathrm{ml}$, không có đáp ứng miễn dịch. Nhóm đã tiêm một mũi vắc xin sau 21 ngày có trung vị nồng độ kháng thể là $69,25 \mathrm{AU} / \mathrm{ml}$, khoảng tứ phân vị dao động từ 38,7 đến 100,75 , nồng độ này cao gấp khoảng 5 lần so với ngưỡng đáp ứng miễn dịch, gấp 12,4 lần so với nhóm chưa tiêm. Nhóm đã tiêm vắc xin 2 mũi sau 1 tuần có trung vị nồng độ kháng thể là $250 \mathrm{AU} / \mathrm{ml}$, nồng độ này cao hớn so với nhóm đã tiêm 1 mũi khoảng 7 lần $(p<0,001)$, và cao hơn nhóm chưa tiêm 45 lần. Nồng độ kháng thể cao nhất được ghi nhận ở nhóm đã tiêm vắc xin 2 mũi sau 2 tuần với mức $400 \mathrm{AU} / \mathrm{ml}$ cao gấp 1,6 lần so với nhóm đã tiêm vắc xin 2 mũi sau 1 tuần. Tuy nhiên, sự khác biệt này không có ý nghĩa thống kê với $p>0,05$. Tuy nhiên, sau khi đạt nồng độ kháng thể cao nhất vào thời điểm 2 tuần sau khi tiêm mũi 2 , nồng độ kháng thể giảm xuống vào thời điểm 3 tuần sau khi tiêm 2 mũi vắc xin, nồng độ này có trung vị là $123 \mathrm{AU} / \mathrm{ml}$, nhỏ hơn 2 lần so với nồng độ kháng thể tại thời điểm khi tiêm vắc xin 2 mũi sau 1 tuần $(p=0.000$ sự khác nhau này có ý nghĩa thống kê).

\section{BÀN LUẬN}

Việc theo dõi nồng độ kháng thể sau tiêm vắc xin Covid-19 có vai trò quan trọng trong việc đánh giá hiệu quả của vắc xin và xác định mức độ phơi nhiểm trong cộng đồng. Nghiên cứu của chúng tôi đã so sánh sự khác nhau trong các giai đoạn sau khi tiêm vắc xin: chưa tiêm, sau tiêm mũi một 21 ngày, sau tiêm mũi hai 1 tuân, sau tiêm mũi hai 2 tuần, sau tiêm mũi hai 3 tuần. Nghiên cứu của chúng tôi đã chỉ ra tất cả các đối tượng được tiêm vắc xin phòng Covid-19 ở nhóm tiêm 1 và 2 mũi đều có đáp ứng miễn dịch với nồng độ kháng thể $\geq 15 \mathrm{AU} / \mathrm{mL}$, kết quả này giống với kết quả trong thử nghiệm lâm sàng pha 1,2 của vắc xin Astrazeneca, vắc xin ComirnatyTM (Pfizer-BioNTech) và Moderna Covid-19 về khả năng sinh miến dịch sau tiêm [3],[4]. Nồng độ kháng thể cao nhất được ghi nhận ở nhóm đã tiêm vắc xin 2 mũi sau 2 tuần, nồng độ có trung vị cao nhất ở mức $400 \mathrm{AU} / \mathrm{mL}$ cao gấp 1,6 lần so với nhóm đã tiêm vắc xin 2 mũi sau 1 tuần. Kết quả này ở nghiên cứu của chúng tôi về kết quả định lượng kháng thể cũng tương tự kết quả thử nghiệm lâm sàng ở pha 2 , 3 của vắc xin Astrazeneca chỉ ra rằng nồng độ kháng thể cao nhất sau khi tiêm mũi hai 2 tuần, sau đó giảm dần vào các tuần tiếp theo. Một nghiên cứu khác của tác giả Azzi và cộng sự nghiên cứu đã so sánh về nồng độ kháng thể IgG sau khi tiêm 2 tuần 1 mũi vắc xin và sau khi tiêm 2 mũi vắc xin BNT162b2 với thời điểm tiêm vắc xin, kết quả nghiên cứu này tương tự như kết quả của chúng tôi về nồng độ kháng IgG cao nhất vào thời điểm 14 ngày sau khi tiêm 2 mũi vắc xin (trung bình 400) [5]. Mặc dù các nghiên cứu chỉ ra rằng nồng độ kháng thể cao chỉ số quan trọng trong việc bảo vệ cơ thể trước sự xâm nhiễm của vi rút SAR-COVID-2 và các biến thể của nó, tuy nhiên nó không thể loại trừ khả năng bị lây nhiếm vẫn có thể xảy ra khi cơ thể đã sản sinh sinh miễn dịch với nồng độ kháng thể cao. Do đó cần tìm ra sự tương quan giữa nồng độ kháng thể và khả năng bảo vệ cơ thể trước sự xâm nhiê̂m vi rút SAR-COVID-2 [6].

Về đặc điểm theo dõi các tác dụng không mong muốn mà chúng tôi ghi nhận được từ nghiên cứu này, các tác dụng không mong muốn được ghi nhận ở các thời điểm sau khi tiêm vắc xin 1 mũi và 2 mũi là sốt, ớn lạnh, đau đâu, đau mỏi người và đau sưng tại vị trí tiêm. Tỷ lệ các đối tượng xuất hiện đau sưng tại vị trí tiêm và đau mỏi người chiếm tỷ lệ cao hớn ở cả 2 nhóm. Các tỷ lệ tác dụng không mong muốn ít gặp như ớn lạnh, đau đầu sau khi tiêm. Sốt thường gặp hơn ở nhóm sau khi tiêm 2 mũi. Kết quả nghiền 
cứu của chúng tôi có kết quả tương đồng với kết quả ghi nhận trong các thử nghiệm lâm sàng của vắc xin Astrazeneca, kết quả cho thấy các tác dụng không mong muốn có thể xảy ra như sốt, ớn lạnh, đau đầu, sưng đau tại vị trú tiêm sau khi tiêm và tác dụng không mong muốn thường gặp là sưng đau tại vị trí tiêm. Tuy nhiên kết quả của chúng tôi khổng tương đồng về tỷ lệ xuất hiện tác dụng không mong muốn ở nhóm sau khi tiêm 2 mũi vắc xin cao hơn nhóm tiêm lần đầu, ngược lại với kết quả ghi nhận trong tờ hướng dẩn sử dụng vắc xin Astrazeneca, tần xuất xuất hiện phản ứng không mong muốn giảm ở nhóm sau khi tiêm vắc xin ở mũi thứ 2 [7].

\section{KẾT LUÂ̂N}

Nghiên cứu của chúng tôi đã tiến hành quan sát nồng độ kháng thể kháng vi rút SARS-Covid2 trên 80 đối tượng, chúng thấy các tác dụng không mong muốn được ghi nhận ở các thời điểm sau khi tiêm vắc xin 1 mũi và 2 mũi là sốt, ớn lạnh, đau đầu, đau mỏi người và đau sưng tại vị trí tiêm. Tỷ lệ gặp tác dụng không mong muốn ở 2 nhóm nhìn chung là tương đương. Kết quả định lượng IgG của mẫu nghiên cứu cho thấy $100 \%$ các nhóm đã tiêm vắc xin đều có đáp ứng miễn dịch với SAR-COVID-2 ngay từ mũi 1 và cao hơn so với nhóm chưa tiêm ít nhất 12 lần (nhóm tiêm 1 mũi) cho đến 71 lần (nhóm sau tiêm 2 mũi 2 tuần). Tiêm đủ 2 mũi vắc xin giúp cơ thể của các đối tượng nghiên cứu đạt được nồng độ kháng thể cao hơn rõ rệt so với khi tiêm 1 mũi. Nồng độ kháng thể kháng vi rút SARSCovid-2 vào 3 tuần sau tiêm mũi 2 nhỏ hơn so với nhóm sau tiêm vắc xin 2 tuần. Từ kết quả phân tích trên, chúng ta thấy rằng tiêm vắc xin phòng Covid-19 giúp sản sinh kháng thể chống lại vi rút SARS-CoV-2. Tuy nhiên, lượng kháng thể này khác nhau giữa các đối tượng và thay đổi theo thời gian sau khi tiêm phòng.

\section{TÀl LIỆU THAM KHẢO}

1. Forchette, L., W. Sebastian, and T. Liu, $A$ Comprehensive Review of COVID-19 Virology, Vaccines, Variants, and Therapeutics. Curr Med Sci, 2021: p. 1-15.

2. Jimenez, M., N.E. Campillo, and M. Canelles, COVID-19 Vaccine Race: Analysis of AgeDependent Immune Responses against SARS-CoV2 Indicates that more than Just One Strategy May Be Needed. Curr Med Chem, 2021. 28(20): p. 3964-3979.

3. Widge, A.T., et al., Durability of Responses after SARS-CoV-2 mRNA-1273 Vaccination. N Engl J Med, 2021. 384(1): p. 80-82

4. World Health, O., mRNA vaccines against COVID-19: Pfizer-BioNTech COVID-19 vaccine BNT162b2: prepared by the Strategic Advisory Group of Experts (SAGE) on immunization working group on COVID-19 vaccines, 22 December 2020. 2020, World Health Organization: Geneva.

5. Azzi, L., et al., Anti-SARS-CoV-2 RBD IgG responses in convalescent versus naïve BNT162b2 vaccine recipients. Vaccine, 2021. 39(18): p. 2489-2490.

6. Coughlin, M.M. and B.S. Prabhakar, Neutralizing human monoclonal antibodies to severe acute respiratory syndrome coronavirus: target, mechanism of action, and therapeutic potential. Rev Med Virol, 2012. 22(1): p. 2-17.

7. World Health, 0 . Interim recommendations for use of the ChAdOx1-S [recombinant] vaccine against COVID-19 (AstraZeneca COVID-19 vaccine AZD1222 Vaxzevria ${ }^{\mathrm{TM}}$, SII COVISHIELD ${ }^{\mathrm{TM}}$ ): interim guidance, first issued: 10 February 2021, updated: 21 April 2021, last updated: 30 July 2021. 2021, World Health Organization: Geneva.

\section{KẾT QUẢ HÓA TRI PHÁC ĐỒ Có TS-1 TRONG ĐIỀU TRI UNG THƯ DẠ DÀY GIAI ĐOẠN MUỘN}

\section{TÓM TẮT}

Mục tiêu: Đánh giá kết quả điều trị ung thư da dày giai đoạn muộn bắng hóa tri phác đồ có TS-1. Đối tượng và phương pháp nghiên cứu: 43 bệnh nhân

\author{
${ }^{1}$ Bệnh viện đa khoa tỉnh Nam Định \\ ${ }^{2}$ Trung tâm Y học hạt nhân và Ung bướu, Bệnh viện \\ Bach Mai \\ Chịu trách nhiệm chính: Đỗ Thái Hiền \\ Email: hiendothaih8@gmail.com \\ Ngày nhận bài: 21.6.2021 \\ Ngày phản biên khoa hoc: 16.8.2021 \\ Ngày duyệt bài: 24.8.2021
}

\section{Đỗ Thái Hiền' ${ }^{1}$ Phạm Cẩm Phương ${ }^{2}$}

được chẩn đoán ung thư da dày giai đoạn muộn, 31 bệnh nhân được điều trị bằng TS-1 kết hợp Cispaltin và 12 bệnh nhân được điều trị bằng TS-1 đơn thuân tại bệnh viện $K$ và Bệnh viện Bạch Mai từ tháng 1 năm 2020 đến tháng 4 năm 2021. Kết quả: Tuổi trung bình của nhóm nghiên cứu là 60,1 tuổi. Tỉ lệ nam/nữ là 2,9/1. 88,4\% bệnh nhân có chí số toàn trang $\mathrm{PS}=0$ 1. Ớ nhóm bệnh nhân được điều trị phác đồ TS-1 kết hợp Cisplatin cho kết quả $51,6 \%$ đáp ứng toàn bộ, không có đáp ứng hoàn toàn, $35,5 \%$ bệnh ổn định, $4 \%$ bênh tiến triển. Ớ nhóm điêu tri phác đồ TS-1 đơn trị cho kết quả $16,7 \%$ đáp ứng toàn bộ, không có đáp ứng hoàn toàn, $66,6 \%$ bênh ổn đinh và $2 \%$ bênh tiến triển. Kết luận: Phác đồ chứa TS-1 có hiệu quả kiểm 